\title{
Analisis Sistem Informasi Akuntansi Penerimaan Kas (Studi Kasus Rumah Sakit Dr. R Ismoyo Kendari)
}

\section{Oleh}

\author{
Hasbuddin $^{1}$, Sitti Nurnaluri ${ }^{2}$, Esy Karsini ${ }^{3}$ \\ E-mail: esy.karsini@gmail.com
}

\begin{abstract}
This research is titled about how the systems and procedures for accounting cash receipts run by Dr.R Ismoyo Hospital, Kendari. By comparing the cash receipt system in theory with reality. The type of data used is qualitative data which is data in the form of explanations or questions that or not in the form of numbes obtained from Dr.R Ismoyo's hospital. The source of data in this study is data primer and data secondary. Data collection methods used were interviews and documentation In conducting this research the writer uses the descriptive analysis method, which is an analytical method that describes the condition of the object under stud based on the available facts, by collecting, processing, and presenting data so that it can provide a clear picture of the object under study.

Based on the result of the discussion it can be conclude that the accounting system for cash receipt applied by Dr.R Ismoyo Hospital in Kendari is in accordance with the theory described covering the network procedures, related functions including cashier functions, treasurer functions and accounting functions of documents and records used in cash receipt. The system and procedure for receiving cash has been implemented well but there are shortcomings namely the cashir section still uses the manual system
\end{abstract}

Keywords: accounting information systems, cash receipts.

\section{PENDAHULUAN}

Rumah sakit merupakan instansi yang bergerak di bidang kesehatan, menurut Keputusan Menteri Kesehatan Republik Indonesia No.983/Men.Kes/SK/XI/1992 rumah sakit adalah salah satu organisasi sektor publik yang bergerak dalam bidang pelayanan jasa kesehatan yang mempunyai tugas melaksanakan suatu upaya kesehatan secara berdaya guna dan berhasil dengan mengutamakan atau mementingkan upaya penyembuhan dan pemulihan yang telah dilaksanakan secara serasi dan terpadu, oleh pihak rumah sakit dalam upaya peningkatan dan pencegahan penyakit serta upaya perbaikan.

Dalam menjalankan kegiatan pelayanan kesehatan, rumah sakit memiliki sistem diantaranya adalah sistem infomasi akuntansi, yang meliputi sistem penerimaan kas, sistem pengeluaran kas dll. Seluruh sistem dijalankan sebagai prosedur dalam suatu perusahaan termasuk rumah sakit Dr.R Ismoyo Kendari. Sistem tersebut harus disusun dan di kelola dengan baik untuk memberikan informasi yang dibutuhkan bagi manajemen perusahaan.

Sistem informasi akuntansi mempunyai peran yang besar bagi suatu perusahaan. Diperlukan sistem yang memadai untuk mengawasi kegiatan penerimaan dan pengeluaran kas akan efektif dan tidak terjadi penyalahgunaan kas. Sistem informasi akuntansi mempunyai bagian yang sangat penting dalam suatu perusahaan. Dalam suatu perusahaan sistem informasi yang sedang berjalan berfungsi untuk menghasilkan laporan kepada pihak-pihak yang berkepentingan terhadap aktivitas ekonomi dan kondisi perusahaan, mengetahui maju 
mundurnya suatu perusahaan dari laporan keuangan perusahaan tersebut, pemakai informasi akuntansi biasanya dipakai secara ekstern maupun intern. (Mulyadi, 2013).

Sumber utama penerimaan kas Rumah Sakit Tk IV Dr R Ismoyo Kendari diantaranya diperoleh dari instalansi rawat inap dan rawat jalan. Pada sistem penerimaan kas rawat jalan dan rawat inap, telah dibuat sistem untuk mengatur urutan-urutan prosedur penerimaan kas rawat inap dan rawat jalan. Rumah sakit ini sebenarnya telah menggunakan sistem terkomputerisasi pada beberapa bagian yang berhubungan dengan penerimaan kas.

Sistem terkomputerisasi yang digunakan berupa efisiensi pemakaian kode rekening untuk mengurangi kesalahan penjurnalan. Akan tetapi untuk bagian kasir masih menggunakan sistem lama atau manual yang dalam prosesnya masih menggunakan kode rekening lama yang sebenarnya sudah tidak diperlukan lagi. Bahkan terjadinya adanya kesalahan yang timbul karena faktor human error mengingat begitu banyaknya nota-nota rawat jalan dan rawat inap, maupun kuitansi-kuitansi yang dihitung, sehingga kesalahan dalam pencatatan transaksi maupun pencatatan biaya bisa terjadi. Hal ini mungkin bisa jadi koreksi bagi sistem penerimaan kas rumah sakit Dr.R Ismoyo kendari. Mengingat rumah sakit merupakan instansi yang penerimaan kas berlangsung setiap hari, kendala tersebut memungkinkan terjadinya kesalahan serta berpengaruh terhadap laporan harian kas. Karena pentingnya pendapatan kas dari rawat inap dan rawat jalan, maka rumah sakit ini memerlukan suatu sistem yang baik untuk mengelola penerimaan kas rawat inap dan rawat jalan. Dengan adanya sistem yang baik ini, dapat dihasilkan laporan kas harian yang tepat waktu.

Berdasarkan uraian mengenai latar belakang penelitian maka dapat dirumuskan masalah dalam penelitian ini Adalah: Bagaimana penerapan sistem informasi akuntansi penerimaan kas Rumah Sakit Dr.R. Ismoyo Kendari?. Adapun tujuan dari penelitian ini adalah untuk mengetahui bagaimana sistem dan prosedur akuntansi penerimaan kas dijalankan dengan menelusuri jaringan prosedur yang membentuk sistem akuntansi penerimaan kas, fungsi yang terkait, dokumen dan catatan akuntansi yang digunakan.

\subsection{Sistem}

\section{KAJIAN PUSTAKA}

Krismiaji (2015:1) pengertian sistem adalah rangkaian komponen yang dikoordinasikan untuk mencapai serangkaian tujuan, yang memiliki karakteristik meliputi; komponen, atau sesuatu yang dapat diihat, didengar atau dirasakan; proses, kegiatan untuk mengkoodinasikan komponen yang terlibat dalam sebuah sistem; tujuan, sasaran akhir yang ingin dicapai dari kegiatan koordinasi komponen tersebut.

\subsection{Informasi}

Mardi (2011:13), Informasi adalah data yang diolah menjadi bentuk yang lebih berguna dan lebih berarti bagi yang menerimanya.Azhar Susanto (2017:38), Informasi adalah hasil pengolahan data yang memberikan arti dan manfaat.

\subsection{Akuntansi}

American Institute of Certified Public Accountant (AICPA) mendifinisikan akuntansi sebagai seni pencatatan, penggolongan dan pengikhtaran dengan cara tertentu dan dalam ukuran moneter, transaksi dan kejadian-kejadian yang umumnya bersifat keuangan dan termasuk menafsirkan hasil-hasilnya.

\subsection{Sistem informasi}

Krismiaji (2015:16) pengertian sistem informasi adalah cara-cara yang diorganisasikan untuk mengumpulkan, memasukan, mengolah dan menyimpan data, dan cara-cara yang diorganisasikan untuk menyimpan, mengelola, mengendalikan, dan melaporkan infomasi untuk mencapai tujuan. 


\subsection{Sistem Informasi Akuntansi}

Pengertian Sistem Informasi Akuntansi menurut Susanto (2017:80), dapat didefinisikan sebagai kumpulan (integrasi) dari sub-sub sistem/ komponen baik fisik maupun nonfisik yang saling berhubungan dan bekerja sama satu sama lain secara harmonis untuk mengolah data transaksi yang berkaitan dengan masalah keuangan menjadi informasi keuangan.

\subsubsection{Tujuan Dan Fungsi Sistem Informasi Akuntansi}

Hall (2010:14) mengatakan tujuan sistem informasi akuntansi adalah sebagai berikut :

1. Untuk mendukung fungsipekerjaan dari manajemen Pekerjaan yang dimaksudkan disini adalah mengenai tanggung jawab dari pihak manajemen untuk mengatur sumber daya perusahaan. Sistem informasi akuntansi menyediakan informasi mengenai pemakaian sumber daya kepada pengguna eksternal dengan menggunakan laporan keuangan dan laporan lainnya.

2. Untuk mendukung pengambilan keputusan bagi manajemen Sistem informasi akuntansi memberikan informasi yang penting untuk digunakan manajer dalam membuatkeputusan bagi perusahaannya.

3. Untuk mendukung kegiatan sehari-hari perusahaan

4. Untuk menerapkan sistem pengendalian intern, memperbaiki kinerja dan tingkat keandalan informasi akuntansi dan untuk menyediakan catatan lengkap mengenai pertanggungjawaban.

Sistem informasi akuntansi menyediakan informasi kepada pegawai untuk membantu menyelesaikan pekerjaan mereka dengan efektif dan efisien

Hall (2010:14) selain memiliki tujuan, sistem informasi akuntansi akan melaksanakan fungsi utamanya, yaitu sebagai berikut:

1. Mengumpulkan dan menyimpan data dari semua aktivitas dan transaksi perusahaan.

2. Memproses data menjadi informasi yang berguna bagi pihak manajemen

3. Memanajemen data-data yang ada ke dalam kelompok-kelompok yang sudah ditetapkan oleh perusahaan.

4. Mengendalikan pengendalian data yang cukup sehingga asset dari suatu organisasi atau perusahaan terjaga.

5. Penghasil informasi yang menyediakan informasi yang cukup bagi pihak manajemen untuk melakukan perencanaan, mengeksekusi perencanaan dan mengendalikan aktivitas.

\subsubsection{Komponen Sistem Informasi Akuntansi}

Menurut Susanto (2017:207), adalah sebagai berikut:

\section{Hardware}

Hardware (perangkat keras) merupakan merupakan peralatan phisik yang dapat digunakan untuk mengumpulkan, memasukan, memproses, menyimpan dan mengeluarkan hasil pengolahan data dalam bentuk informasi.

\section{Software}

Software(perangkat lunak) adalah kumpulan dari program-program yang digunakan untuk menjalankan aplikasi tertentu pada komputer, sedangkan program merupakan kumpulan dari perintah-perintah komputer yang tersusun secara sistematis.

\section{Brainware}

Sumber Daya Manusia (SDM) SI/SIA merupakan sumber daya yang terlibat dalam pembuatan sistem informasi, pengumpulan dan pengolahan data, pendistribusian dan pemanfaatan informasi yang dihasilkan oleh sistem informasi tersebut. Beberapa kelompok SDM suatu organisasi yang terlibat dalam beberapa aktivitas diatas secara garis besar dapat dikelompokan kedalam pemilik dan pemakai sistem informasi. 
1) Pemilik Sistem Informasi

Pemilik sistem informasi merupakan sponsor terhadap dikembangkannya sistem informasi. Mereka biasanya disamping bertanggung jawab terhadap biaya dan waktu yang digunakan untuk pengembangan serta pemeliharaan sistem informasi, mereka juga berperan sebagai pihak penentu dalam menentukan diterima atau tidaknya sistem informasi.

2) Pemakai Sistem Informasi

Para pemakai sistem informasi sebagian besar merupakan orangorang yang hanya akan menggunakan sistem informasi yang telah dikembangkan seperti operator dan manajer (end user). Para pemakai akhir sistem informasi tersebut menentukan masalah yang harus dipecahkan, kesempatan yang harus ambil, kebutuhan yang harus di penuhi, dan batasan-batasan bisnis yang harus termuat dalam sistem informasi. Mereka juga cukup memperhatikan tayangan aplikasi di komputer baik dalam bentuk form input maupun outputnya.

\section{Prosedur}

Prosedur merupakan rangkaian aktivitas atau kegiatan yang dilakukan secara berulangulang dengan cara yang sama. Prosedur merupakan komponen dari sistem informasi baik itu sistem informasi manajemen atau sistem informasi akuntansi yang sering dilupakan, padahal tanpa prosedur yang benar sistem informasi sehebat apapun tidak akan berjalan sebagaimana mestinya.

\section{Database}

Database Merupakan kumpulan data-data akurat, relevan, tepat waktu dan lengkap sesuai dengan kebutuhan kebutuhan pemakai, yang tersimpan didalam media penyimpanan di suatu perusahaan atau didalam perusahaan. Database yang dibangun harus dihitung perkiraan volumenya untuk dapat menentukan kapasitas hardisk yang dibutuhkan dan tipe prosesor yang cocok untuk menangani data sejumlah yang diperlukan. Dengan menentukan terlebih dahulu informasi yang diperlukan. Berdasarkan kebutuhan informasi tersebut maka harus diketahui bagaimana proses untuk menghasilkan informasi tersebut.

\section{Jaringan Komputer dan Telekomunikasi}

Komponen-komponen yang digunakan dalam jaringan komunikasi data satu sama lain harus berintegrasi secara harmonis atau bersinergi membentuk jaringan komunikasi data dalam sistem informasi akuntansi. Komponen jaringan komunikasi data yang harus bersinergi misal antara hubungan yang digunakan, saluran komunikasi dan Network Card (LAN Card). Keharmonisan teknologi yang digunakan dalam jaringan komunikasi harus sesuai dengan hardware yang digunakan. Komponenkomponen dan fungsi dari sistem telekomunikasi yaitu:
a.) Fungsi sistem telekomunikasi
b.) Pemroses komunikasi
c.) Software komunikasi

\subsubsection{Manfaat Sistem Informasi Akuntansi}

Menurut Hall (2010:14), sebuah sistem informasi akuntansi yang dirancang dengan baik dapat memberikan kegunaan yaitu sebagai berikut:

1. Untuk mendukung fungsi pengelolaan manajemen (to support the stewardship function of management).

2. Mendukung operasional perusahaan sehari-hari (to support the finn's day-to-day operations).

3. Mendukung pengambilan keputusan manajemen (to support management decision making) 
Teknologi informasi mempunyai dampak paling dominan terhadap lingkungan bisnis. Adapun manfaat dari sistem informasi akuntansi menurut Hall (2010:15) adalah sebagai berikut :

1. Menyediakan informasi yang akurat dan tepat waktu

2. Meningkatkan kualitas dan mengurangi biaya produksi, baik barang maupun jasa yang dihasilkan

3. Meningkatkan keefektifitasan dan keefisiensian dalam bekerja dibandingkan mengolah data secara manual

4. Meningkatkan kemampuan dalam mengambil keputusan

5. Meningkatkan sharing pengetahuan

6. Untuk menerapkan sistem pengendalian internal, memperbaiki kinerja dan tingkat keandalan (reliability)

Untuk menyediakan catatan lengkap mengenai pertanggung jawaban (akuntanbilitas)

\subsubsection{Karateristik Kualitas Sistem Informasi Akuntansi}

Menurut Hall (2010:12) menyebutkan bahwa karakteristik kualitas informasi akuntansi adalah sebagai berikut:

1. Relevan

Informasi yang relevan merupakan informasi yang perlu diketahui untuk memberikan pemahaman yang baru. Laporan yang hanya bersifat sementara dan selanjutnya tidak relevan harus dihentikan pembuatannya.

2. Tepat Waktu

Umur informasi merupakan faktor yang kritikal dalam menentukan kegunaannya. Informasi harus tidak lebih tua dari periode waktu tindakan yang didukungnya.

3. Akurat

Informasi harus bebas dari kesalahan yang sifatnya material. Kesalahan-kesalahan material ada ketika jumlah informasi yang tidak akurat menyebabkan pemakainya melakukan keputusan yang buruk atau gagal melakukan keputusan yang diperlukan.

4. Lengkap

Tidak ada bagian informasi yang esensial bagi pengambilan keputusan atau pelaksanaan tugas yang hilang. Informasi yang tidak lengkap bisa menimbulkan kesulitan, karena informasi yang tidak disertakan itu akan menjadi unsur ketidakpastian yang benar.

5. Ringkasan

Informasi harus diagregasi agar sesuai dengan kebutuhan pemakai. Informasi yang ringkas dan mengikhtisarkan data yang relevan menunjukkan bidang-bidang penyimpangan terhadap tingkat normal, standar, atau yang direncanakan merupakan bentuk informasi yang banyak diperlukan oleh para pemakai informasi akuntansi.

\subsection{Penerimaan Kas}

Mulyadi (2013:55) Penerimaan kas adalah kas yang diterima perusahaan baik yang berupa uang tunai maupun surat-surat berharga yang mempunyai sifat dapat segera digunakan, yang berasal dari transaksi perusahaan maupun penjualan tunai, pelunasan piutang, atau transaksi lainnya yang dapat menambah kas perusahaan. "sumber penerimaan kas terbesar suatu perusahaan dagang berasal dari transaksi penjualan tunai.

\subsection{Sistem Penerimaan Kas}

Menurut Mulyadi (2013:462) menyampaikan bahwa dalam sistem akuntansi penerimaan kas terdiri dari:

a. Fungsi yang terkait

b. Dokumen yang digunakan

c. Catatan akuntansi yang digunaka 
d. Jaringan prosedur yang membenruk sistem

\subsection{Sistem Informasi Akuntansi Penerimaan Kas}

Mulyadi (2010:321) Sistem informasi akuntansi penerimaan kas adalah suatu transaksi yang menimbulkan bertambahnya saldo kas dan bank milik perusahaan yang diakibatkan adanya penjualan hasil produksi, penerimaan piutang maupun hasil transaksi yang menyebabkan bertambahnya kas.

\subsection{Simbol-Simbol Flowchart}

Simbol masukan /keluaran (input/output symbol) mewakili alat atau media yang memberikan input untuk atau mencatat output dari suatu pemrosesan.

Tabel 2.1 Simbol Input/Output

\begin{tabular}{|c|c|l|}
\hline Simbol & Nama & \multicolumn{1}{|c|}{ Keterangan } \\
\hline & Dokumen & $\begin{array}{l}\text { Simbol yang menyatakan input } \\
\text { berasal dari dokumen dalam } \\
\text { bentuk kertas atau output } \\
\text { dicetak kertas }\end{array}$ \\
\hline & $\begin{array}{l}\text { Rangkap dari } \\
\text { sebuah dokumen }\end{array}$ & $\begin{array}{l}\text { Rangkap dokumen } \\
\text { diindikasikan dengan } \\
\text { pemberian nomor dokumen } \\
\text { pada sudut sebelah kanan } \\
\text { simbol dokumen }\end{array}$ \\
\hline & $\begin{array}{l}\text { Input/Output, jurnal } \\
\text { dan buku besar }\end{array}$ & $\begin{array}{l}\text { Simbol ini menggabarkan } \\
\text { setiap fungsi input atau output } \\
\text { dalam flowchart program. } \\
\text { Simbol ini juga digunakan } \\
\text { untuk menggabarkan jurnal } \\
\text { dan buku besar dalam } \\
\text { flowchart }\end{array}$ \\
\hline
\end{tabular}

Sumber: Sugiyono (2015) 


\subsection{Kerangka Pikir}

\section{Skema 2.1}

Kerangka Pikir Penelitian

Kerangka Pikir

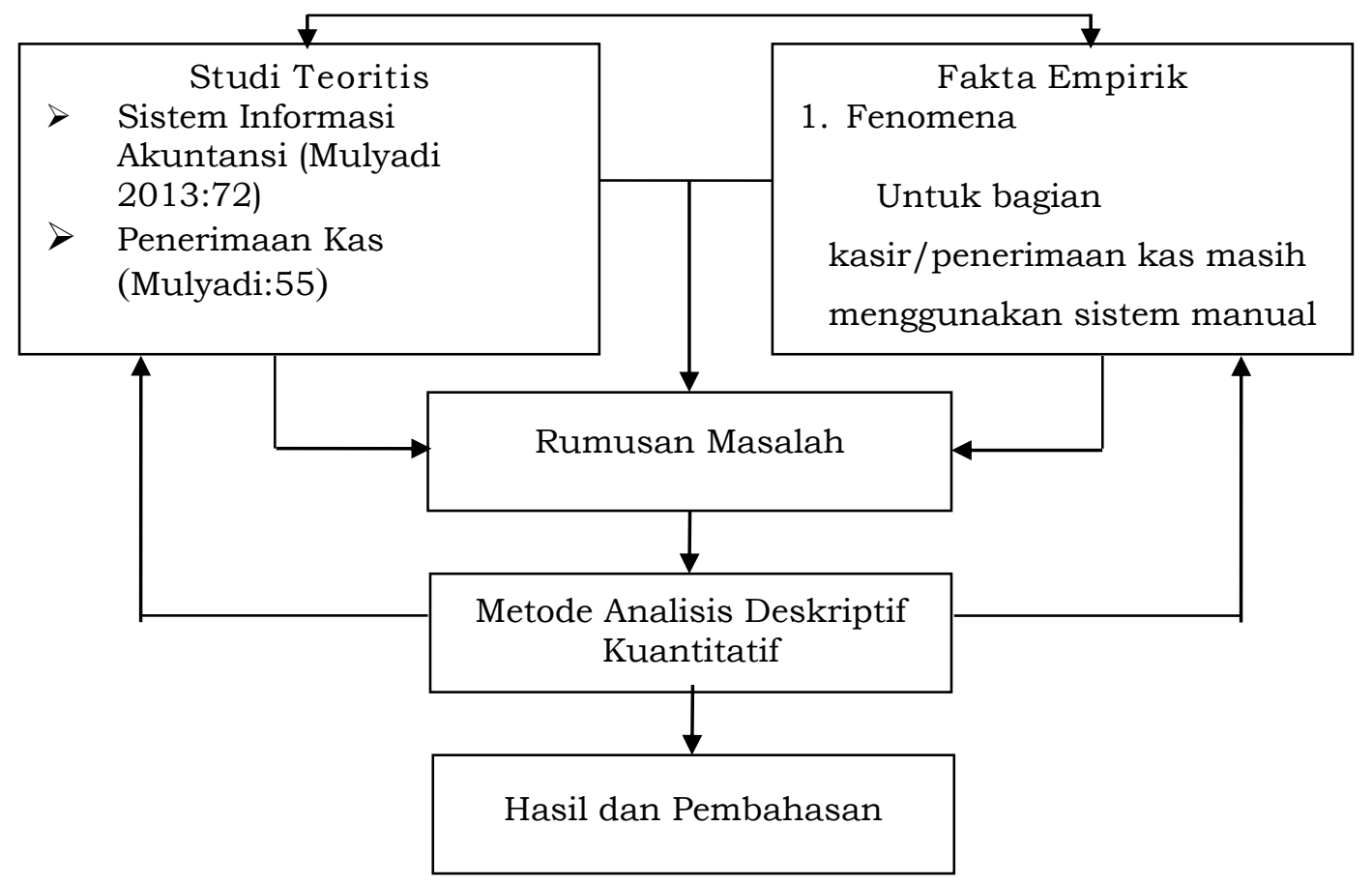

III. METODE PENELITIAN

Lokasi penelitian dilakukan di Rumah Sakit Dr R Ismoyo berada dalam wilayah Korem143/Haluoleo Kendari. Rumah Sakit Dr R Ismoyo Kendari beralamat lengkap di Jalan Laute Nomor 1 Kecamatan Mandonga Kendari, NomorTelpon 0401-324716 Fax : 04013122029 KodePos : 93111. Objek penelitian yang dipilih adalah analisis sistem informasi akuntansi penerimaan kas.

Jenis data yang digunakan dalam penelitian ini terdiri dari jenis yakni data kualitatif. Data kualitatif adalah data yang berupa penjelasan atau pernyataan yang tidak berbentuk angka yang diperoleh dari Rumah Sakit Dr R Ismoyo melalui wawancara dan sumber lainnya yang relevan dengan judul proposal yang diambil oleh peneliti. Sumber data yang digunakan dalam penelitian ini adalah Data primer dan data sekunder. Data primer adalah adalah data dalam penelitian ini yaitu berupa hasil wawancara pada Rumah Sakit Dr R Ismoyo. Data sekunder dalam penelitian ini berupa dokumentansi seperti profil Rumah Sakit Dr R Ismoyo.

\section{HASIL PENELITIAN DAN PEMBAHASAN}

\subsection{Hasil Penelitian}

\subsubsection{Deskripsi Sistem Informasi Penerimaan Kas Pada Rumah Sakit Dr.R. Ismoyo Kendari}

Sistem penerimaan kas secara umum yang dilakukan oleh Rumah sakit Dr.R. Ismoyo adalah sebagai berikut:

1. Pasien mengambil karcis

2. Pasien melakukan registrasi dan berobat 
3. Petugas keuangan mencatat seluruh biaya pelayanan pasien kedalam poliklinik

4. Petugas keuangan mencatat seluruh karcis kedalam tanda bukti setor.

5. Petugas distribusi melapor kepada koordinator rawat jalan atau rawat inap.

6. Koordinator menandatangani buku klinik dan tanda bukti setor yang telah di cek kebenarannya.

7. Petugas keuangan menyerahkan tanda bukti setor yang telah ditandatangani kepada kasir rawat jalan atau rawat inap.

8. Koordinator rawat jalan menghimpun semua tanda bukti setor dan diserahkan kepada kasir penerimaan rumah sakit .

9. Setelah melakukan pengobatan dan perawatan, pasien melakukan pembayaran sesuai rincian biaya dibagian kasir.

10. Kasir penerimaan mencatat pembayaran pasien dibuku harian dan menerbitkan kuitansi 3 rangkap . rangkap 1 : pasien, rangkap 2: acuan buku harian, rangkap 3 : arsip.

11. Kasir penerimaan menyetor buku harian beserta bukti penerimaan kas kepada bendahara pembantu

12. Bendahara pembantu penerimaan rumah sakit Dr.R. Ismoyo Kendari membuat laporan penerimaan bulanan dan melaporkan ke bendahara umum

13. Bendahara umum penerimaan membukukan penerimaan kas kedalam kas umum dan membuat jurnal.

14. Kasir penerimaan menyerahkan bukti setor yang telah ditanda tangani kepada :

a. Lembar pertama untuk kasir penerimaan

b. Lembar kedua kepada Ka. Akuntansi keuangan

c. Lembar ketiga untuk pemegang kas.

\subsubsection{Jaringan prosedur membentuk sistem penerimaan kas}

"Yang pertama sumber penerimaan kas di rumah sakit Dr.R. ismoyo kendari berasal dari berbagai macam kegiatan seperti penerimaan kas dari rawat jalan dan rawat inap. Prosedur penerimaan kas di RS. Dr. R Ismoyo Kendari melibatkan empat petugas yaitu bagian perawatan, bagian kasir, bagian bendahara, bagian akuntansi. Petugas kasir berfungsi menerima bukti pembayaran yang dilakukan oleh pasien dan memberikan tanda pembayaran pasien (berupa kwitansi dan stempel "LUNAS" dan stempel "Rumah Sakit"). Kemudian yang ditunjukan kepada bagian bendahara untuk diverifikasi kebenarannya. Setelah itu, bagian akuntansi melakukan penyusunan laporan keuangan.”.

\subsubsection{Prosedur Penerimaan Kas Pada Rumah Sakit Dr.R. Ismoyo Kendari}

Berdasarkan wawancara dibagian kepala staff diklat prosedur penerimaan kas secara tunai di RS Dr.R Ismoyo Kendari adalah sebagai berikut: 


\section{Flowcart 1: Prosedur Penerimaan Kas Dari Pelayanan Rawat Jalan}

\section{Rekam Medis}
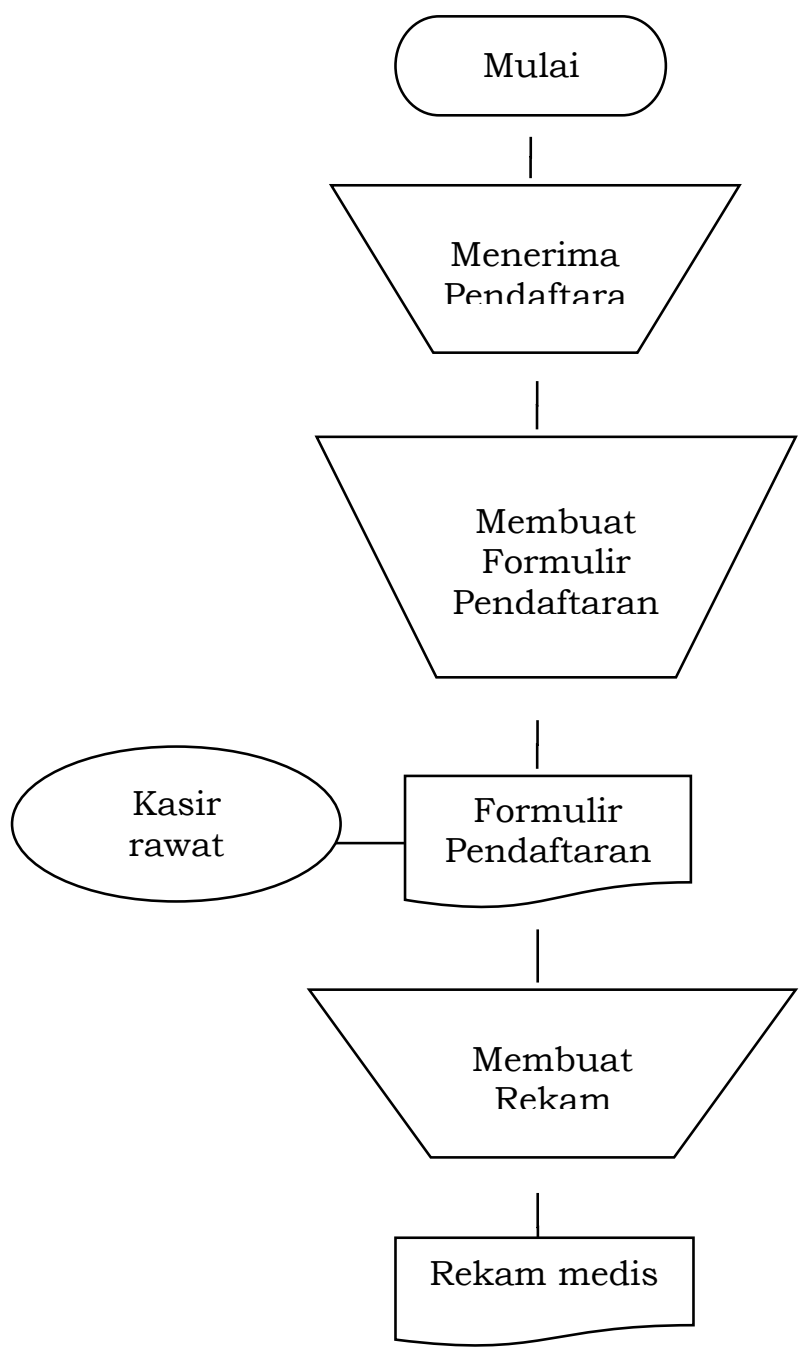

\section{Sumber : Data Diolah Penulis (2019)}

\subsubsection{Dokumen-Dokumen yang Digunakan dalam Sistem Penerimaan Kas}

Menurut wawancara bagian kasir, dokumen yang digunakan dalam proses penerimaan kas di RS. Dr.R Ismoyo Kendari adalah sebagai berikut:

"Dokumen yang digunakan dalam proses penerimaan kas bagian pelayanan rawat inap dan rawat jalan meliputi: dokumen identitas pasien, surat rujukan, lembar tujuan periksa,dan bukti pembayaran".

\subsubsection{Fungsi yang terkait dalam Penerimaan Kas}

Berdasarkan wawancara mengenai fungsi yang terkait dalam penerimaan kas adalah fungsi akuntansi, fungsi bendahara, dan fungsi akuntansi.

\subsubsection{Catatan Akuntansi yang Digunakan di RS. Dr.R Ismoyo Kendari}

"Catatan akuntansi yang digunakan dalam sistem penerimaan kas adalah jurnal penerimaan kas, buku penerimaan dan buku besar". 


\subsection{Pembahasan}

\subsubsection{Jaringan Prosedur yang Membentuk Sistem}

Jaringan prosedur RS. Dr.R Ismoyo kendari sudah terorganisir dengan baik antara prosedur penerimaan kas, prosedur penyetoran kas dan prosedur pencatatan kas. Hal ini berarti telah terdapat pemisahan fungsi yang jelas sehingga masing-masing bagian dan struktur organisasi mempunyai tanggung jawab yang jelas dalam menyusun dan melaksanakan sistem akuntansi penerimaan kas instansi rawat ianp dan rawat jalan pada RS. Dr.R ismoyo Kendari. Keseluruhan prosedur yang membentuk sistem dapat memberikan pelayanan yang memadai kepada pasien.

\subsubsection{Prosedur Penerimaan Kas Pada Rumah Sakit Dr.R Ismoyo Kendari}

Prosedur penerimaan kas rumah sakit Dr.R Ismoyo Kendari sudah baik dimulai dari pasien, melakukan registrasi dibagian rekam medis kemudian melakukan pemeriksaan dibagian pelayanan/dokter, bagian kasir menerima pembayaran dari pasien beserta menerbitkan kuitansi 3 rangkap mengarsip kebuku harian yang akan dilaporkan dan disimpan pada bagian bendahara, bagian akuntansi melakukan pencatatan penerimaan kas dimulai dari jurnal penerimaan kas dan laporan keuangan rumah sakit.

\subsubsection{Dokumen Yang Digunakan Dalam Sistem Penerimaan Kas}

Dokumen-dokumen yang terdapat pada rumah sakit Dr.R. Ismoyo Kendari sudah baik. Hal ini dibuktikan dengan adanya kuitansi sebagai bukti pembayaran pasien dan diotorisasi oleh pihak yang berwenang. Setiap dokumen terdiri dari tiga rangkap yang masing-masing untuk bagian kasir, pasien dan untuk arsip. Akan tetapi, dalam penaganannya masih terdapat kelemahan. Kelemahan yaitu banyaknya kuitansi-kuitansi yang perlu dicatat mengakibatkan kurang telitinya para karyawan dalam melakukan pencatatan. Sehingga seringkali terjadi kesalahan dalam memasukan identitas pasien dan tidak balance antara uang yang diterima dengan laporan kas harian yang dicatat dan dihitung bagian akuntansi.

\subsubsection{Catatan Akuntansi yang Digunakan dalam Sistem Penerimaan Kas}

Catatan yang digunakan dalam penerimaan kas rumah sakit Dr.R Ismoyo Kendari sudah baik. Hal ini dibuktikan adanya Jurnal penerimaan kas yang digunakan untuk mengetahui seluruh transaksi terkait bertambahnya saldo kas rumah sakit. Buku penerimaan digunakan untuk mencatat penerimaan kas yang dibuat oleh bagian bendahara kemudian diserahkan kepada bagian akuntansi sebagai laporan penerimaan kas. Buku besar berfungsi untuk meringkas semua data transaksi yang sudah tertulis didalam jurnal umum. Akan tetapi rumah sakit masih menggunakan pencatatan manual adanya pencatatan penerimaan kas secara manual menyebabkan adanya ketidaksesuaian pencatatan akuntansi yang dicatat dengan bukti penerimaan yang diterima, membuat sering sekali terjadi perbedaan dalam pencatatan kas.

\subsubsection{Evaluasi Terhadap Sistem yang Terkait}

Rumah Sakit DR.R Ismoyo Kendari mempunyai struktur organisasi yang tertulis sehingga telah jelas adanya garis wewenang dan tanggung jawab serta pembagian kerja fungsional. Fungsi pencatatan dan pelaporan dilakukan oleh bagian kasir, bagian bendahara,bagian akuntansi. Fungsi operasional dilakukan oleh bagian rekam medis, bagian keperawatan, dan bagian penunjang medis lainnya Setiap fungsi sudah dijalankan dengan cukup baik oleh masing-masing bagian. 


\subsection{Kesimpulan}

\section{KESIMPULAN DAN SARAN}

Berdasarkan hasil penelitian yang penulis lakukan, maka penulis dapat mengambil kesimpulan sebagai berikut: "Sistem penerimaan kas RS. Dr.R Ismoyo Kendari masih menggunakan sistem manual dibagian kasir, yang sering menyebabkan kesalahan pencatatan dan memengaruhi dalam membuat rekapan dan buku kas umum”.

\subsection{Saran}

Berdasarkan hasil penelitian dan analisa yang dilakukan penulis terhadap sistem informasi akuntansi penerimaan kas pada Rumah Sakit Dr.R.Ismoyo Kendari dapat diambil saran sebagai berikut :

1. Untuk Rumah Sakit Dr.R.Ismoyo ,Rumah sakit diharapkan menggunakan sistem informasi akuntansi terkomputerisasi agar penerimaan kas baik dari rawat inap maupun rawat jalan dapat berlangsung secara efektif.

2. Untuk peneliti selanjutnya, sebaiknya perbanyak referensi teori mengenai sistem informasi akuntansi penerimaan kas yang menggunakan sistem terkomputerisasi, sehingga saat membandingkan teori dengan implementasi tidak ada kesenjangan.

\section{DAFTAR PUSTAKA}

Achmad, Azizah Nur. 2015. Analisis Peranan Sistem Informasi Akuntansi Persediaan Alat-alat Kesehatan Dalam Memenuhi Kebutuhan Rawat Inap(Studi Kasus pada Rumah Sakit Bahteramas Kendari). Jurnal EMBA Vol.1, No.3 ISSN: 2503-3069

American Institute of Certified Public Account (AICPA).2012. Objective of Financial Statement, FASB, Statement. Teori Akuntansi. Jakarta: Raja Grafindo Prakasa.

A Hall, James. 2010. Sistem Informasi Akuntansi, Edisi 4, Jakarta: Salemba Empat

E. Kieso, Donald,Jerry J, Weygandt and Teery D. Warfield, 2011, Intermediate Accounting, Edisi 12 by: Erlangga

Gelinas, Ulrich. 2012. Accounting Information Systems,9thed. South Western Cengage Learning. 5191 Natorp Boulevard Mason, USA. P. 19.

Harahap, Sofyan Syafri. 2011. Teori Akuntansi. Jakarta : Raja Grafindo Persada.

Krismiaji. (2015). Sistem Informasi Akuntansi (Ed. Ke-4). Yogyakarta: UPP STIM YKPN.

Laponsa, Dito Bernandus. 2018. Analisis Sistem Informasi Akuntansi Penerimaan Kas(Studi Kasus pada Koperasi Wahana Murti Sukabumi). Jurnal EMBA Vol.3, No.1 ISSN 2405139

Mardi. 2011. Sistem Informasi Akuntansi.Bogor : Ghalia

Maria, Ika Dana. 2016. Analisis Sistem Informasi Akuntansi (SIA) Pendapatan Rawat Inap Kamar VIP(Studi Kasus pada RSUD Kota Lawang). Jurnal EMBA Vol.4, No.1 ISSN 2304-11

Mulyadi. 2013. Sistem Akuntansi. Cetakan Kelima. Jakarta: Salemba Empat.

Satzinger, Jackson Burd. 2012. System Analisis and Design with the Unified Process. USA: Course Technology, Cengage Learning.

Susanto, Azhar. 2017. Sistem Informasi Manajemen, Bandung: Lingga Jaya.

Sugiyono.2015. Statistika Untuk Penelitian. Bandung: CV. Alfa Beta

Sujarweni,Wiratna. 2015. Statistik Untuk Bisnis \& Ekonomi.Yogyakarta: Pustaka Baru Press.

Undang-Undang Nomor 44 tahun 2009 tentang Rumah Sakit. 